\title{
Las huellas del español en textos alemanes en la época de la colonización: Nikolaus Federmann (1505-1542)
}

\author{
Spanish Loanwords Present in German Texts \\ from the Early Stage of Colonialism: \\ Nikolaus Federmann (1505-1542)
}

\section{Cristina Santana-Quintana \\ Filología Moderna \\ Universidad de Las Palmas de Gran Canaria \\ C/ Pérez del Toro, 1. Las Palmas de Gran Canaria, 35004 \\ cristina.santana@ulpgc.es \\ Orcid ID 0000-0003-2985-2832}

\begin{abstract}
Resumen: Este trabajo se basa en una descripción de las voces españolas presentes en la documentación del cronista alemán Nikolaus Federmann (1505-1542), cuya obra recoge uno de los pocos relatos en alemán sobre la conquista que hace referencia a una etapa temprana del colonialismo. Nos proponemos confeccionar un inventario de las palabras españolas encontradas en el texto seleccionado para luego buscar qué tipo de estrategias y procedimientos son usados y los posibles motivos por los que se opta por estos préstamos. Los resultados de nuestra investigación proporcionan una visión de cómo y por qué se produce la incorporación de estas voces españolas y nos indican que el autor usa el español como una lengua instrumental en las relaciones sociales y económicas vinculadas con las operaciones de carácter comercial y diplomático. Por esta razón se puede suponer que el discurso lingüístico de la lengua española durante la época de la colonización está fuertemente marcado por la funcionalidad.
\end{abstract}

Palabras clave: Colonización. Hispanismos. Préstamos. Estrategias comunicativas. Cronistas alemanes.
RECIBIDO: 28 DE DICIEMBRE DE 2016 ACEPTADO: 14 DE FEBRERO DE 2017
Abstract: This work is an analysis of the Spanish loanwords present in a document by the German chronicler Nikolaus Federmann (1505-1542), whose work refers to an early stage of colonialism. We intend to make an inventory of the Spanish words found in the selected text and study the strategies and procedures used to incorporate Spanish lexicons. Possible reasons for this incorporation are also mentioned. The results of our research provide a vision of how and why the author included these Spanish voices and indicate that the Spanish language became instrumental during the epoch of the colonization. For this reason it is possible to suppose that the linguistic speech of the Spanish language is marked by the functionality.

Keywords: Colonization. Hispanisms. Spanish Loanwords. Communicative Strategies. German Chroniclers. 


\section{INTRODUCCIÓN}

a contribución de los alemanes a la conquista de América fue insignificante, en parte porque Alemania no poseía en aquella época la unidad político-administrativa que hubiera sido necesaria para la colonización de América, a diferencia de lo que ocurría en países como España, Francia o Portugal (Ascarate 10). Esta es la razón por la que existen también pocos autores alemanes que reflejen esta etapa histórica. Entre los existentes son dignos de nombrar los siguientes tres autores: Ambrosius Alfinger, Joerg von Hohermuth y Nikolaus Federmann, cuyas actividades en América del Sur tuvieron cierta importancia histórica (Avellaneda 1990, 43; Nitschack 107).

Nuestro trabajo es innovador porque va a tomar en consideración textos redactados en alemán por viajeros alemanes a América, un tema aún poco estudiado. En nuestro caso abarcamos la huella de palabras españolas que aparecen en el texto de uno de estos viajeros, Nikolaus Federmann (1505-1542). La decisión de seleccionar para este trabajo a este autor en concreto se basa, por tanto, en su relevancia y en que su obra es uno de los pocos relatos en alemán sobre la conquista que hace referencia a una etapa temprana del colonialismo y sobre la exploración de la región entre la costa atlántica y el valle en el que se fundó Bogotá (Nitschack 97).

La llegada a América de los alemanes implicó el contacto lingüístico y cultural con los españoles y otras culturas europeas, así como con los indígenas. El testimonio de Nikolaus Federmann ofrece una traslación de la perspectiva directa a través de sus experiencias personales con la incorporación de nuevas palabras y vocablos, lo que nos permite llevar a cabo un análisis de la asimilación y registro de esas voces. En nuestro estudio nos proponemos como objetivos: 1) confeccionar un repertorio de las palabras españolas encontradas en el texto seleccionado; 2) una vez concretado dicho inventario de voces, buscar qué tipo de estrategias y procedimientos son usados, así como el tipo de léxico y 3 ) encontrar las posibles causas de este uso y los motivos por los que se opta por estos préstamos.

Para lograr nuestro objetivo, comenzamos el presente estudio en primer lugar con la contextualización del texto y con la presentación del autor y su relación con el Nuevo Mundo. Posteriormente, exponemos la metodología de trabajo con la presentación del Corpus diacrónico del español (CORDE) y con la confección de un repertorio de las palabras españolas encontradas en el documento, una vez concretado dicho inventario de voces. Con los resultados encontrados, analizamos qué tipo de estrategias y procedimientos son em- 
pleados, así como el tipo de léxico. Seguidamente se razonan las posibles causas de este uso y los motivos por los que se opta por estos préstamos, para terminar exponiendo las conclusiones obtenidas.

\section{ConTEXTUalización}

La obra de Nikolaus Federmann Indianische Historia. Ein schöne kurtzweilige Historia Niclaus Federmanns des Füngern von Ulm erster raise relata su primera expedición en el noroeste de Venezuela en 1530 y es considerada el documento clave de los primeros contactos europeos, en que se narran por primera vez hechos sobre la población indígena de Falcón, Lara y Yaracuy (Arvelo 675). El Reino de la Nueva Granada fue descubierto por tres expediciones, dos españolas y una alemana, en la que Nikolaus Federmann, al servicio de la empresa de la Casa de los Welser - un grupo de banqueros alemanes atraídos por el Nuevo Mundo y la leyenda del Dorado (Otte 153-54; Wagner 7; Avellaneda 1987, 385; Ascarate 57)-, es mandado a la provincia de Venezuela, donde se convierte en el gobernador y donde explora y funda varias ciudades.

El libro comprende el primer viaje de Federmann a América, y tiene un gran valor testimonial, antropológico e histórico porque describe el primer contacto que se tiene de los Llanos y de las zonas que hoy comprenden los estados venezolanos de Falcón y Lara. El relato recoge informaciones sobre la expedición al interior de Venezuela en los años 1530-1531 y fue redactado durante una estancia en Alemania antes de su vuelta a Venezuela como capitán general. Fue publicado póstumamente -quince años después de la muerte de Federmann- en Hagenau por la imprenta de Sigmund Bund en el año 1557.

El proceso de colonización de la Nueva España comenzó con el asentamiento y la fundación de las primeras ciudades. Los textos de este periodo son testigos de la necesidad de comunicarse a través de la incorporación de indigenismos y del empleo de las voces patrimoniales hispánicas que inician un proceso de americanización (Frago 524). La participación de Federmann y de sus hombres en la conquista fue muy activa (Avellaneda 1987, 386), y para nuestro trabajo es importante mencionar el contacto que mantuvo siempre con españoles en sus expediciones. Así, por ejemplo, la primera expedición de Federmann estuvo compuesta por 39 hombres nacidos en las provincias de España y una pequeña representación de otras nacionalidades europeas, en total siete (Friede 58; Avellaneda 1987, 388). Durante este primer viaje, Federmann abandonó su puesto para buscar el ansiado oro de El Dorado, llevando 
consigo a 110 españoles. Después de volver a Europa por un corto periodo de tiempo, regresa de nuevo con el fin de buscar por segunda vez El Dorado (1535-1536), haciéndose acompañar por cuatrocientos hombres (Ascarate 58).

Federmann, que tenía conflictos y pleitos con la Corona española, entiende la necesidad de redactar un relato según los patrones de los textos españoles, puesto que su finalidad era básicamente la misma (Ribas 125). Kiefhaber introduce en su dedicatoria explícitamente la certificación autóptica cuando afirma que el relato recoge la narración de lo que Federmann ha visto en su viaje y que ha sido registrada por un notario oficial y posteriormente traducida al alemán. Según se afirma en el prólogo del texto, el relato es la traducción alemana del acta oficial de un notario español que Federmann mismo tradujo a su lengua. Este protocolo notarial en español no ha sido encontrado. La traducción al alemán podría estar destinada a los Welser, ante quienes Federmann tenía sin duda que rendir cuentas. Por esta razón, el autor tiene que ampliar el texto original redactado por el notario, que recogía solo las peripecias del viaje por el interior de Venezuela, para incluir sus dos desplazamientos. En la dedicatoria de Kiefhaber se puede leer que Federmann escribió su relato a requerimiento del emperador, lo que permite aproximar este texto a las relaciones de las Indias españolas (Ribas 125).

Esta circunstancia hay que unirla al complejo entorno en el que se encuentra nuestro autor, dado que vive en un mundo indígena nuevo rodeado de otras culturas europeas y de una gran variedad lingüística. Los alemanes se comportaron siempre como extranjeros entre españoles, portugueses y holandeses, por lo cual es muy probable que adoptasen todo tipo de lexemas a través de la lengua de las naciones implicadas en la conquista e incluso voces indígenas. En el caso del texto de Nikolaus Federmann, por dar un ejemplo, es notable la constante presencia de palabras españolas (48 términos), francesas (1 término) así como indigenismos (12 términos). Los préstamos indígenas encontrados en el texto como aca cay, barbacoa, batata, bejuco, bobí, cacique, canoa, bamaca, juca, macana, maiz o naboría designan una nueva realidad, por lo que su adopción se basaba en una mera necesidad, pues era la única salida semántica que tenían para poder llenar un vacío frente a una nueva fauna, flora, costumbres, moda o alimentos (Mejías 13). La palabra de origen francés batel se ha encontrado en 484 ocasiones en textos españoles entre los años de estudio (1525-1557) según datos del CORDE, por lo que se puede entender que ya estaba integrada en la lengua española. La hipótesis de la utilización de voces indígenas se podría justificar como una estrategia para reforzar el grado de autenticidad del texto, es de- 
cir, como medio para producir la presencia y la autenticidad de la experiencia (Ribas 156; Baisch 179) como también hicieron muchos cronistas españoles (Vaquero de Ramírez 19; Cáceres-Lorenzo 1084).

\section{MATERIALES Y MÉTODO}

\section{El Corpus Diacrónico del Español (CORDE)}

El Corpus diacrónico del español (CORDE) es un banco de datos de la lengua española que recopila aproximadamente un total de 300 millones de palabras desde los orígenes del idioma hasta el año 1974 agrupadas en tres grandes etapas históricas: Edad Media, desde los orígenes hasta 1491 con un 21 \%; Siglos de Oro, desde 1492 hasta 1712 con un 28 \%; y Época Contemporánea, desde 1713 hasta 1974 con un 51 \% (Molina Salinas/Sierra Martínez 311; Sánchez Lancis 163). Este corpus abarca textos de una gran diversidad de géneros distribuidos en prosa y verso, y dentro de cada modalidad se subdividen en textos narrativos, líricos, dramáticos, científico-técnicos, históricos, jurídicos, religiosos, periodísticos, etc.

Hemos basado nuestro análisis en este corpus porque se trata uno de los recursos más importantes del que se puede disponer para el estudio de la lengua española (Sánchez Sánchez/Domínguez Cintas 140). Usaremos el CORDE para documentar las palabras y calificarlas, así como para obtener de cada consulta el número de textos totales, distribución geográfica, cronológica y temática.

\section{Inventario de voces españolas}

Tras confeccionar un índice de las palabras españolas encontradas en el texto seleccionado, del que hemos apartado los topónimos, utilizamos el CORDE justificando los límites cronológicos entre los años 1525 y 1575, dado que son las fechas próximas al trabajo del autor. Como se puede observar en el inventario de voces españolas de la tabla 1, en la primera columna aparece el texto con la palabra española encontrada y entre paréntesis la página del libro de la edición con la que se ha trabajado (ver bibliografía). Cada vocablo es examinado según los siguientes indicadores que nos ofrece el CORDE: primera datación de la aparición de los lexemas (D), el porcentaje (\%) y el número de casos (K). La siguiente columna muestra el tipo de léxico como se recoge en el CORDE (T): prosa histórica (A), prosa de sociedad (B), prosa jurídica (C), prosa narrativa (D), 
prosa científica (E) y verso lírico (F). En la última columna hemos agrupado los elementos léxicos en campos semánticos (S): marineras o marinerismos $(\mathrm{M})$, administrativo, económico y comercial (D), vida social o cultural (v) y finalmente militar (T). El signo "+" después de una palabra significa que esta se repite con frecuencia a lo largo del texto. Este es el caso de indios, con 140 menciones, y pueblo oder flecken, con 74 repeticiones. Hay que mencionar que el sustantivo fortuna se recoge en el texto con el sentido de borrasca.

\begin{tabular}{|c|c|c|c|c|c|}
\hline TEXTO Y PÁGINA & D & $\%$ & K & $T$ & 5 \\
\hline $\begin{array}{l}\text { Schiffer oder Marineros (7) } \\
\text { die Maryneros oder schiffer (83) }\end{array}$ & 1540 & 100 & 5 & B & M \\
\hline $\begin{array}{l}\text { Rescat, oder schatzung und losung (7) } \\
\text { Rescat und losung (8) } \\
\text { Rescat oder bezahlung (58) } \\
\text { Bezalung und rescat (64) }\end{array}$ & 1535 & 96.55 & 304 & A & D \\
\hline $\begin{array}{l}\text { Indios }(11+) \\
\text { Indios oder innwoner (33) }\end{array}$ & 1535 & 89.80 & 12781 & A & v \\
\hline $\begin{array}{l}\text { Gubernator }(12,13,15,16,81) \\
\text { Gubernatores und hauptleüt (51) } \\
\text { Gubernator oder seinem Statthalter (13) }\end{array}$ & 1535 & 86.89 & 557 & A & D \\
\hline Factor $(10,12,15,162,196,197)$ & 1535 & 97.11 & 404 & A & D \\
\hline Als Factor, Contador, und Thersorero, das seind, & 1535 & 97.29 & 108 & A & D \\
\hline factor, zoll und schatzmaister (15) & 1525 & 80.71 & 636 & A & D \\
\hline Pobladores oder einwoner (15) & 1535 & 79.30 & 196 & A & V \\
\hline $\begin{array}{l}\text { Gubernation }(5,15,16,55) \\
\text { Gubernation oder herrschung }(55)\end{array}$ & 1548 & 80.20 & 4 & c & D \\
\hline Sitten und Ceremonias (16) & 1536 & 81.81 & 144 & A & v \\
\hline $\begin{array}{l}\text { Indios Principales oder Herren (23) } \\
\text { Principales (34) }\end{array}$ & 1535 & 95.77 & 68 & A & v \\
\hline Capitan general (16) & 1527 & 100 & 92 & C & D \\
\hline $\begin{array}{l}\text { Flecken oder Pueblo (55) } \\
\text { Pueblo oder flecken }(17+) \\
\text { Puebles (13) }\end{array}$ & 1535 & 70.40 & 7293 & A & v \\
\hline
\end{tabular}


SANTANA-QUINTANA. HUELLAS DEL ESPAÑOL EN TEXTOS COLONIALES ALEMANES

\begin{tabular}{|c|c|c|c|c|c|}
\hline TEXTOYPÁGINA & D & $\%$ & K & T & s \\
\hline $\begin{array}{l}\text { Naturales oder einwoner }(9) \\
\text { Naturales oder Indios }(13,41) \\
\text { Naturales oder innwoner }(54) \\
\text { Innwoner oder Naturales (18) }\end{array}$ & 1535 & 88.78 & 3055 & A & v \\
\hline $\begin{array}{l}\text { Ain königliche kamer und hoffgerich, wölches sie } \\
\text { Audiencia Real haissen (10) }\end{array}$ & 1535 & 83.68 & 118 & E & D \\
\hline Corrent, oder lauffend (10) & 1535 & 98.93 & 279 & $\mathrm{E}$ & M \\
\hline prospero oder dienlich (10) & 1553 & 66.66 & 14 & D & D \\
\hline $\begin{array}{l}\text { Pilot oder laiter des schiffs }(10,11) \\
\text { Piloto, also haißt der iaitter des schiffs (85) } \\
\text { Pilot (110) }\end{array}$ & 1545 & 100 & 5 & B & M \\
\hline $\begin{array}{l}\text { die Costa des lands }(11) \\
\text { diser Costa oder gestadt }(11) \\
\text { Costa oder gestadt des Mörs }(68,79,80) \\
\text { Costa oder gestade del Algarbe }(84)\end{array}$ & 1535 & 95.05 & 5055 & E & M \\
\hline Carabel (14) & 1535 & 99.65 & 585 & A & M \\
\hline $\begin{array}{l}\text { Armada }(6,15) \\
\text { armada de su Majestet (111) }\end{array}$ & 1535 & 96.80 & 2396 & A & M \\
\hline Ordinari oder gemainglich (11) & 1540 & 96.27 & 491 & A & D \\
\hline Municion (21) & 1527 & 100 & 18 & c & $\mathrm{T}$ \\
\hline $\begin{array}{l}\text { Eschlauos und verkauffte leütt (22) } \\
\text { Esclavos oder verkauffte knecht ( } 54 \text { ) } \\
\text { Navoria oder Eschlavos, also haissen ihre verkauften leütt (60) }\end{array}$ & 1527 & 85.67 & 1160 & A & v \\
\hline $\begin{array}{l}\text { Amonestationes (23) } \\
\text { Amonestation oder ersüchung (53) }\end{array}$ & 1535 & 96.96 & 96 & A & D \\
\hline Rodellas oder Tartschen (24) & 1535 & 87.69 & 114 & A & T \\
\hline Defensa, wehre und beschutzung (24) & 1535 & 98.23 & 668 & A & $\mathrm{T}$ \\
\hline Mariscos oder mörmuscheln (28) & 1527 & 100 & 9 & A & M \\
\hline Carne humana, das ist menschen flaisch essen (32) & 1535 & 96.72 & 236 & A & v \\
\hline Credito oder glaub (41) & 1552 & 92.15 & 47 & D & D \\
\hline
\end{tabular}


SANTANA-QUINTANA. HUELLAS DEL ESPAÑOL EN TEXTOS COLONIALES ALEMANES

\begin{tabular}{|l|c|c|c|c|c|}
\hline \multicolumn{1}{|c|}{ TExTo y pácliNA } & D & $\%$ & K & T & S \\
\hline Poblation (42) & 1519 & 77.77 & 14 & C & V \\
\hline $\begin{array}{l}\text { Remedio oder vorteyl (24) } \\
\text { Remedio oder hilfe (43,68, 81) } \\
\text { Remedio oder mittel (53) }\end{array}$ & 1554 & 97.68 & 3504 & D & M \\
\hline Opinion oder meynung (45) & & & & \\
\hline Descubridor, oder erfinder (51) & 1557 & 98.87 & 176 & D & D \\
\hline Relationen, oder fürträgen (51) & 1535 & 90.10 & 82 & A & V \\
\hline Proposito (51) & 1535 & 85.34 & 99 & A & D \\
\hline $\begin{array}{l}\text { Victoria oder der sig (52) } \\
\text { Victoria (186) }\end{array}$ & 1551 & 98.28 & 229 & D & D \\
\hline $\begin{array}{l}\text { Laguna oder Mors (59) } \\
\text { Laguna (61) } \\
\text { Laguna oder See (67) } \\
\text { Laguna oder dem See (68) }\end{array}$ & 1535 & 98.75 & 1504 & A & T \\
\hline Navigation oder schiffung (60) & 1535 & 77.74 & 594 & E & M \\
\hline Einig oder Conforme (71) & 1549 & 97.65 & 250 & A & D \\
\hline $\begin{array}{l}\text { Confederiert, oder bündtnus gemacht (33) } \\
\text { Confederiert (39, 65) } \\
\text { Confederiert oder verbunden (71, 81) }\end{array}$ & 1555 & 99.81 & 2160 & D & M \\
\hline $\begin{array}{l}\text { Mandaments oder speiß (76) } \\
\text { Mandaments, proviandt und speis (64, 78) } \\
\text { Mandament oder speiß (84) }\end{array}$ & 1528 & 100 & 169 & F & M \\
\hline Notario Scribano publico (80) & 1535 & 95.87 & 2648 & C & D \\
\hline \begin{tabular}{l} 
Reparo (82) \\
\hline Fortuna oder ungewittter (84)
\end{tabular} & 1535 & 94.59 & 35 & A & D \\
\hline $\begin{array}{l}\text { Calma und abgang des windts (84) } \\
\text { Calma und gantz ohn allen windt (84) }\end{array}$ & 1538 & 91.11 & 82 & C & D \\
\hline Patron unser schiffs (84) & 1535 & 95.62 & 175 & A & D \\
\hline $\begin{array}{l}\text { Continuieren (9) } \\
\text { Continuieren oder volstrecken (84) }\end{array}$ & 998.78 & 81 & C & M \\
\hline
\end{tabular}

Tabla 1. Registro de palabras españolas 


\section{RESULTADOS}

El inventario de voces recopiladas de la tabla 1 cumple con las condiciones adecuadas para este tipo de análisis, ya que existe un buen número de términos recogidos en el intervalo histórico objeto de análisis (1525-1557). De los préstamos extranjeros encontrados en el texto, la mayoría son españoles, 48 términos, seguidos de los indigenismos (12) y por último una palabra francesa.

Del estudio llevado a cabo se extrae primero que en el relato de Federmann se repite constantemente el uso de pares de palabras en la combinación palabra española (o latinismo) con la palabra alemana, es decir, que el autor se preocupa de explicar o traducir la palabra en cuestión. Esta estrategia es muy habitual en los textos cronísticos de temática americanista (ver Alvar López, Hernández, Frago, Bravo García/Cáceres-Lorenzo). Según se observa en la tabla 1, estos valores se acompañan de una voz alemana a través de las conjunciones “o" (oder) como Schiffer oder Marineros, Rescat oder bezablung, Pobladores oder einwoner, Indios Principales oder Herren, Flecken oder Pueblo, Naturales oder einwoner, Corrent, oder lauffend, prospero oder dienlich, Rodellas oder Tartschen, etc., y en algunos casos con " $\mathrm{y}$ " (und) como Rescat und losung, Gubernatores und hauptleüt, Sitten und Ceremonias, Eschlauos und verkauffte leütt, Defensa, webre und beschutzung o Calma und abgang des windts. Pero en ambos casos no se expresan valores de exclusión ni de adición, respectivamente. En la mayoría de las ocasiones, el autor intenta acercar los términos extraños a sus compatriotas por medio de las comparaciones y en términos de igualdad, pero resulta llamativo que ya una vez mencionado por primera vez y dado por supuesto que el lector ya sabe de qué se trata, este uso se repita constantemente a lo largo de todo el texto con el mismo binomio una vez ya conocido el significado.

Sin embargo y como contraste, reproduce en muchos otros casos el término en español sin ningún tipo de aclaración y sin traducción como Die Gubernation, Capitan general, Carabel, Armada, Municion, Poblation, Proposito, Notario Scribano publico o Reparo. Parece que estos términos estuvieran perfectamente asimilados por el autor, ya que se usan con naturalidad, ni se explican ni se definen en los textos alemanes. Parecen ser conocidos y estar aceptados sin tratar de crear una palabra descriptiva en su propio idioma o sin su equivalente en alemán que haga referencia a una realidad o a elementos conocidos en Alemania. El contexto de cohabitación posibilitaba que los extranjeros 
aprendieran español -al menos los que convivían en las ciudades o en las encomiendas con los españoles- durante todo el siglo XVI. La convivencia se evidencia en la influencia española, en la modificación de algunos significados de sus propias palabras y también en la incorporación de préstamos castellanos al vocabulario de los conquistadores (Bravo García/Cáceres-Lorenzo 43).

En varias ocasiones encontramos la adaptación como procedimiento por el cual se asimilan aquellas voces que tienen en español una correspondencia fonética bastante aproximada con independencia del significado. Esa adaptación está condicionada por la cercanía fonética de los significantes del término español y del alemán, como por ejemplo Navigation o Relationen. Esta traslación de términos castellanos al alemán se hace en algunas ocasiones con una traducción directa con arreglo a la fonética alemana; en cambio, en otras se producen equívocos quizá por no conocer el sentido de dicho vocablo o expresión, o incluso desconocer la grafía del original, así por ejemplo escribe Maryneros, Rescat, Corrent, Ordinari, Poblation, Mandaments o Scribano. También se aprecia el uso de palabras españolas germanizadas morfosintácticamente asimilándolo al paradigma de los verbos alemanes con la terminación "-ieren" como en Confederiert o Continuieren. Hay que recordar, por un lado, que no se trataba de un lingüista o de un autor literario ni tampoco pretendía serlo; y que su forma de escribir es directa, pobre en expresión y limitada en recursos literarios, lo que conlleva a una lectura reiterativa (Rodríguez Monegal 170; Ribas 22).

La frustración de los estamentos indianos (religiosos/sacerdotes, conquistadores, colonizadores y funcionarios) ante la falta de comunicación con los indios trae como consecuencia la obligación de aprender la lengua indígena (Bravo García/Cáceres-Lorenzo 51). Quizás por tal motivo encontramos también muchas palabras indígenas en el texto de Federmann como aca cay, barbacoa, batata, bejuco, bobio, cacique, canoa, bamaca, juca, macana, maí o naboría. No obstante, en nuestro estudio nos interesa por qué el autor, habiendo nombrado con anterioridad la equiparación de la palabra española con el significado en alemán de esclavos Eschlauos und verkauffte leütt y Esclavos oder verkauffte knecht, utiliza el valor de Naboría (origen taíno) con el de esclavos en español, para luego distanciarse de la palabra al mostrar que existe un matiz diferente utilizando el pronombre posesivo "su" (ihre) e intenta dejar patente que el objeto en sí no es justamente igual al objeto designado por el término alemán empleado como sinónimo: "Navoria oder Eschlavos, also haissen ihre verkauften leütt". 
La consulta en el CORDE de estas voces nos permite comprobar en la tabla 1 el grado de frecuencia de los vocablos de origen español usados por $\mathrm{Ni}$ kolaus Federmann en los textos de procedencia española de la época entre 1525 y 1557: rescat (304 casos), indios (12 781 casos), factor (404 casos), thersorero (636 casos), pobladores (196 casos), ceremonias (144 casos), pueblo (7 293 casos), naturales (3 055 casos), costa (5 055 casos), carabel (585 casos), armada (2 396 casos), esclavos (1 160 casos), etc. Sin embargo, esta consulta también nos permite constatar que algunas palabras tenían poco uso de manera general como marineros (5 casos), gubernation (4 casos), prospero (14 casos), pilot (5 casos), municion (18 casos), mariscos (9 casos), o remedio (14 casos), pero que según la Real Academia Española son palabras de origen hispano. El texto de Federmann puede resultar interesante por usar de forma tan pronta este vocabulario que hace referencia principalmente al campo léxico relacionado con el mar y el mundo militar.

\begin{tabular}{|l|c|c|l|c|c|}
\hline \multicolumn{1}{|c|}{ Tema (CORDE) } & No & \multicolumn{1}{c|}{ CAMPO SEMÁntico } & \multicolumn{1}{c|}{ No $^{\circ}$} & \% \\
\hline A. Prosa histórica & 27 & 55.1 & M. Marineras, marinerismos & 13 & 27 \\
\hline B. Prosa de sociedad & 2 & 4.1 & D. Administrativo, económico y comercial & 21 & 43.7 \\
\hline C. Prosa jurídica & 9 & 18.4 & V. Vida social o cultural & 10 & 20.9 \\
\hline D. Prosa narrativa & 6 & 12.3 & T. Militar & 4 & 8.4 \\
\hline E. Prosa científica & 4 & 8.1 & & & \\
\hline F. Verso lírico & 1 & 2 & & & \\
\hline
\end{tabular}

Tabla 2. Temas y campos semánticos

Según los datos que nos refleja el CORDE, recogidos en la tabla 2, podemos observar que la mayoría de los textos catalogados en esta época con las palabras españolas empleadas por Federmann pertenecen a la prosa histórica (55.1 \%), seguida de una prosa jurídica (18.4\%). Este dato nos muestra parte de la historia lexicológica de la lengua, ya que nos permite comprender la historiografía textual y literaria que se forjaron en el proceso de conquista y colonización americanas. No obstante, lo que nos ofrece un dato importante es el campo semántico al que pertenecen estas palabras. En el que se atestigua mayor número de palabras españolas es el referente al ámbito administrativo-económi- 
co-comercial (43.7 \%); le sigue el tema relacionado con el mar, marinerismos o lenguaje de las galeras (27\%); en tercer lugar, la vida social o cultural (20.9\%); y, por último, los términos restantes pertenecen a la vida militar (8.4\%).

\section{DisCUSIÓN}

Los pasos dados y los criterios establecidos para elaborar una nómina de 48 vocablos nos permiten vislumbrar la existencia de un léxico de uso global relacionado con los diferentes aspectos administrativos, económicos, culturales o sociales así como referentes al mundo de las galeras o marinerismos, que tanta importancia tuvieron para las ciudades del Nuevo Mundo.

Los lexemas utilizados por Nikolaus Federmann forman parte de un compendio de vocabulario eminentemente práctico, destinados a viajeros y comerciantes principalmente, y son fiel reflejo de la necesidad cotidiana en aquel momento como son la corte, las notarías, los puertos, las embajadas o en las representaciones diplomáticas (Corvo Sánchez 114). Las informaciones sobre el Nuevo Mundo que nos proporcionan los primeros documentos dependen de los intereses de los descubridores, conquistadores y colonizadores. La situación en la que se encuentran los autores de la conquista los obliga de alguna manera a ajustar su forma de hablar, acomodándose al entorno que los rodea para, de este modo, poder expresar valores, actitudes e intenciones hacia los demás (Giles 131). Los intereses que quedan reflejados en el texto de Federmann son predominantemente administrativo-económicocomercial (43.7 \%) como rescat, gubernatores, factor, contador, thersorero, gubernation, capitan general, Audiencia Real, prospero, amonestationes, credito, relationen, conforme, confederiert, mandaments, notario scribano publico o Reparo; y no es de extrañar, ya que los alemanes buscaban solo establecer relaciones comerciales en las nuevas colonias. Las circunstancias bajo las cuales viajaron en general los alemanes a través del Atlántico difería de las de españoles, franceses, y homólogos portugueses. La expedición alemana de la conquista y descubrimiento no tenía ambiciones imperiales realistas (Ascarate 41; Ribas 77), sino que los objetivos de sus expediciones iban destinados a conseguir rápidamente beneficios.

Estos objetivos puramente comerciales les obligaban a establecer una comunicación que forzaba a aprender voces españolas para lograr el mutuo entendimiento, y así queda reflejado en los lexemas referentes a la vida social o cultural (20.9\%): indios, pobladores, ceremonias, indios principales, pueblo, na- 
turales, eschlauos, poblation o Descubridor. Por otro lado, la época que nos ocupa es una época en la que el transporte por mar cuenta mucho más que el transporte terrestre, el comercio al que aludimos es precisamente el marítimo y nos referimos más bien a las voces sobre la vida en el mar (27\%), es decir, tipos de barcos, enfermedades frecuentes entre los marineros, castigos, así como lexemas referentes a los fenómenos atmosféricos como marineros, pilot, costa, carabel, armada, mariscos, remedio, laguna, navigation, fortuna, calma o patron.

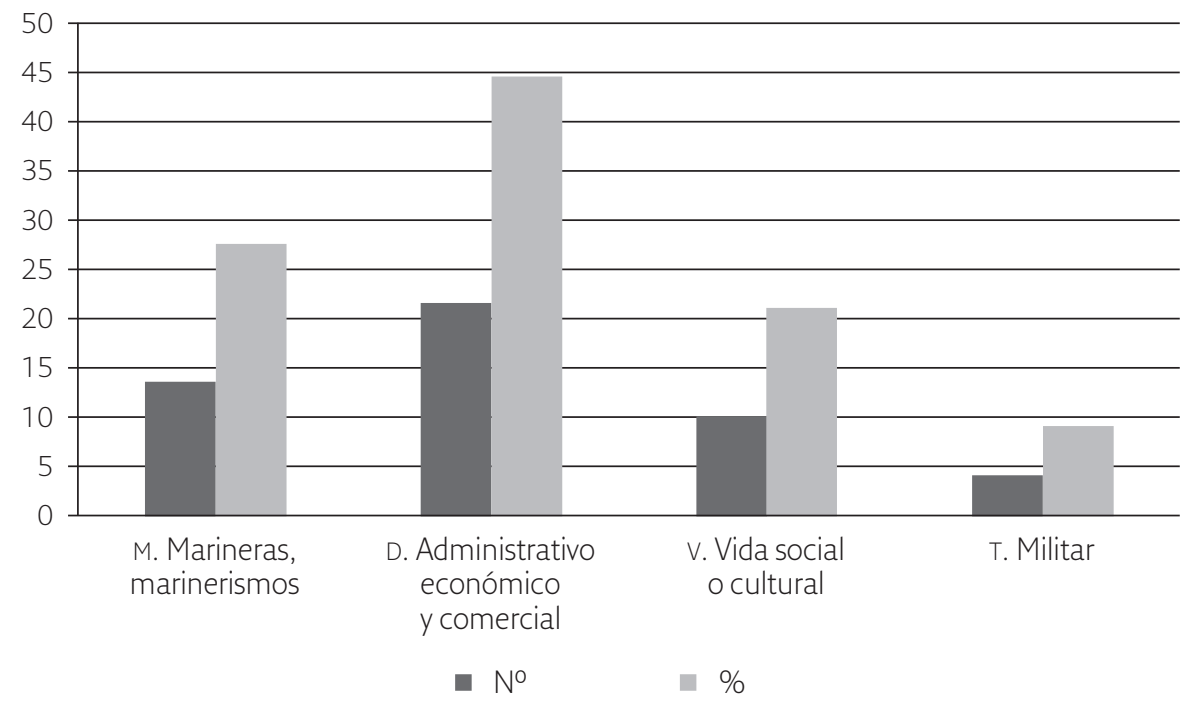

Tabla 3. Número y \% del campo semántico

La tabla 3 nos lleva a concluir que la mayor parte de estos vocablos nombran elementos relacionados con actividades propias y características del proceso de la conquista, como la presencia de personal encargado de la administración, y de la economía de la colonia, como gobernadores y secretarios oficiales Todos estos campos semánticos tienen en común que hacen referencia a temas relacionados directamente con el Nuevo Mundo, puesto que forman parte de documentos oficiales en los que se emplea el lenguaje jurídico y administrativo de la época. El conocimiento de estos términos y su asimilación queda patente en la obra de Federmann al hacer uso de estas lexías de procedencia española con naturalidad, sin a veces explicarlas ni definirlas como Die Gubernation, Capitan general, Proposito, Notario Scribano publico o Reparo. 


\section{CONCLUSIÓN}

Las razones por las que se adoptan préstamos para designar realidades desconocidas para los destinatarios están sujetas: a la necesidad, ya que los autores tienen que informar eficazmente; a la inteligibilidad y a la economía, pues han de ser comprendidos por lectores ajenos a la realidad americana, y deben limitar el uso de voces autóctonas; y a la calidad, escogiendo la mejor denominación entre todas las posibles (Pérez-Salazar 611). Por un lado, el texto de Nikolaus Federmann responde a algunas de estas motivaciones, dado que en parte debe escribir para rendir cuentas de sus expediciones, y por otro lado no tiene un destinatario concreto sino cualquier lector interesado. En principio la naturaleza del texto de Federmann es más bien testimonial, le estimulaba el deseo de transmitir una información veraz e insiste en la certificación de la verdad, basada en el testimonio (Ribas 22).

La utilización de Federmann de voces españolas no se debe en absoluto al desconocimiento de la palabra correspondiente en alemán, como podría suceder con la utilización de indigenismos al encontrarse en la situación de tener que nombrar en los textos un objeto o ser vivo, una actividad o experiencia que no pertenecía a su marco de conocimiento. De hecho, es conocido que la influencia del español nunca ha dejado una huella profunda en el lenguaje alemán (Wis 629). De acuerdo con el Etymologisches Wörterbuch der deutschen Sprache de Kluge-Mitzka (1960) alrededor de 600 términos alemanes provienen del francés, algo más de 300 del italiano y del inglés un tercio, y, por último, alrededor de 70 palabras del español. Los textos cronísticos son un campo fecundo para los influjos léxicos, aunque esto no implica que hayan logrado una difusión amplia y duradera (Procopio/Mota/Coan 13).

Otra de las razones para el cambio de código, es decir, para intercalar palabras españolas en el texto, se puede deber también a la necesidad de enfatizar, como un recurso para codificar citas que aparecen en el discurso, acotar, añadir emoción o aumentar el interés de la comunicación, ya que hemos podido comprobar que los hispanismos encontrados en el texto de Federmann no añadían palabras nuevas al alemán, sino que sustituían palabras del alemán. Los cronistas debían acumular información sobre una sociedad lejana y la transmitían a un público culturalmente próximo y geográficamente remoto, que ignora cómo es esa cultura y siente curiosidad por conocerla. La trascendencia de este tipo de publicación estriba, por tanto, en que estaba pensada también para un público lector interesado en las noticias del Nuevo Mundo y, por tal motivo, Federmann intenta transmitir al público nacional el exotismo 
de sus viajes, describiendo las experiencias que en principio eran difíciles de describir y totalmente novedosas. Esta capacidad narrativa del autor incluso confería un interés especial a estas noticias lejanas -oídas o leídas- frente a la inmediata imagen resultante de un fugaz contacto directo (Del Pino Díaz 2). Se percibe que el uso del binomio palabra española seguida de su significado en alemán en el texto de Nikolaus Federmann es una característica evidente de la producción lingüística por la adopción de voces de las lenguas que entran en contacto. Cada hablante toma, según el momento o la memoria, los elementos que necesita y que no posee o no recuerda, o que son más efectivos en relación con la realidad a la que se desea referir (Jiménez Ramírez 121).

En resumen, hemos de señalar que la obra aquí señalada no es solo importante para conocer una parcela nada desdeñable de la historia lexicológica de la lengua española, sino también para comprender tanto la historia sociocultural, como la historiografía textual y literaria que se forjaron en el proceso de conquista y colonización americana. Se ha llevado a cabo una visión de cómo se produce la incorporación de las voces españolas en el texto del cronista alemán Nikolaus Federmann y, sin duda, las razones por las que se opta por la utilización de préstamos son complejas y las opiniones de los investigadores muy variadas. Mayoritariamente se habla del need-filling motive, o sea de necesidad (Anttila 155; Bobda 383; Hock 409; González-Cruz 238; Shukla/Connor-Linton 279). Sin embargo, los resultados de nuestro estudio parecen confirmar que el uso de voces españolas no estaba basado en la necesidad como factor determinante. El cambio de un idioma a otro no siempre está originado por falta de recursos lingüísticos, sino que a veces sirve como un marcador para mostrar solidaridad étnica o para enfatizar, elaborar una idea y comunicar expresiones idiomáticas o dirigirse a una persona determinada (Ramírez 104). Nuestro análisis ha revelado que, en realidad, la propensión al préstamo se adquiere más bien a través de la socialización en una comunidad concreta, y no está tanto en función de las necesidades léxicas; o lo que es lo mismo, los factores sociales parecen desempeñar un papel fundamental (Romaine 66-67; González-Cruz 238). Cabría entender entonces que, cuando el cronista usa la palabra española en lugar de optar por su equivalente alemán, parece estar indicándonos, consciente o inconscientemente, su grado de imbricación con la sociedad y la cultura que le rodea y su actitud positiva hacia esta.

Los resultados de nuestra investigación proporcionan una visión de cómo y por qué se produce la incorporación de estas voces españolas y podemos aventurar que Nikolaus Federmann no siente como extraño el léxico español 
utilizado. En el texto analizado queda reflejado que el autor usa el español como una lengua instrumental en las relaciones sociales y económicas vinculadas con las operaciones de carácter comercial y diplomático. Por esta razón se puede afirmar que la lengua empleada por Federmann durante las expediciones narradas fuera sin duda el español, y que su discurso lingüístico está fuertemente marcado por la funcionalidad.

\section{OBRAS CITADAS}

Alvar López, Manuel. Americanismos en la Historia de Bernal Díaz del Castillo. Madrid: Ediciones de cultura hispánica, 1990.

Anttila, Raimo. Historical and Comparative Linguistics. Amsterdam: John Benjamins Publishing, 1989.

Arvelo, Lilliam. "Change and Persistence in Aboriginal Settlement Patterns in the Quibor Valley, Northwestern Venezuela (Sixteenth to Nineteenth Centuries)". Ethnohistory 47.3/4 (2000): 669-704.

Ascarate, Richard John. "Extreme Foreignness: German Constructions of Latin America from the Early Modern to the Postmodern". PhD Thesis. University of California, 2005.

Avellaneda Navas, Jose Ignacio. "The Men of Nikolaus Federmann: Conquerors of the New Kingdom of Granada". The Americas 43.4 (April 1987): $385-94$.

Avellaneda Navas, Jose Ignacio. Los Compañeros de Federmann: cofundadores de Santa Fe de Bogotá. Bogotá: Tercer Mundo editores, 1990.

Baisch, Martin. "Wissen, Indexikalität und Neugier in Hans Stadens BrasilienBericht". Dynamiken des Wissens. Ed. Klaus W. Hempfer. Rombach Wissenschaften, Reihe Scenae 6. Freiburg i. Br.: Rombach, 2007. 163-85.

Bobda, Augustin Simo. "The Meaning of English Words across Cultures, with a Focus on Cameroon and Hong Kong". Fournal of Multilingual and Multicultural Development 30.5 (2009): 375-89.

Bravo García, Eva M., y M. Teresa Cáceres-Lorenzo. El léxico cotidiano en América a través de las relaciones geográficas de indias: Tierra firme y América del sur, s. ХVI. Bern: Peter Lang, 2013.

Cáceres-Lorenzo, M. Teresa. "Indoamericanismos de uso general en documentos españoles americanos (1502-1560): propuesta de clasificación y resultados". Bulletin of Spanish Studies 90.7 (2013): 1079-90.

CORDE: Real Academia Española. Banco de datos [en línea]. Corpus diacrónico del español. <http://www.rae.es> [14 de febrero de 2015]. 
Corvo Sánchez, M. José. "Breve historia de la lexicografía bilingüe española y alemana hasta el siglo XIX”. Philologia Hispalensis 22.1 (2008): 113-39.

Del Pino Díaz, Fermín. "Texto y dibujo: la Historia indiana del jesuita Acosta y sus versiones alemanas con dibujos". Fahrbuch für Geschichte Lateinamerikas 42 (2005): 1-31.

Federmann, Nikolaus. "Indianische Historia". N. Federmanns und H. Stades. Reisen in Südamerica 1529 bis 1555. Ed. Dr. Karl Klüpfel. Stuttgart: Literarischer Verein, 1859. 2-166.

Frago, Juan Antonio. "Sobre la criollización del español de América: apuntes documentales y metodológicos". Boletín de Filología 37 (1998): 523-39.

Friede, Juan. Los Welser en la conquista de Venezuela. Caracas/Madrid: Edime, 1961.

Giles, Howard. "Accommodation Theory: Some New Directions". York Papers in Linguistics 9 (1982): 105-36.

González-Cruz, M. ${ }^{a}$ Isabel. "Hispanismos y canarismos en un corpus de textos ingleses sobre Canarias". Lexis 37.2 (2013): 229-68.

Hernández, Esther. Vocabulario en lengua castellana y mexicana de Fray Alonso de Molina: estudio de los indigenismos léxicos y registro de las voces españolas internas. Madrid: CSIC, 1996.

Hock, Hans Henrich. Principles of Historic Linguistics. Berlin: Mouton de Gruyter, 1991.

Jiménez Ramírez, Félix. "El español en la Suiza alemana: características léxicas de la segunda generación de hispanohablantes". ELUA 14 (2000): 117-50.

Mejías, Hugo Antonio. "Préstamos de lenguas indígenas en el español hispanoamericano del siglo XVII". Tesis doctoral. State University of New York, 1978.

Molina Salinas, Claudio, y Gerardo Eugenio Sierra Martínez. "Hacia una normalización de la frecuencia de los corpus CREA y CORDE". Revista Signos 48.89 (2015): 307-31.

Nitschack, Horst. "La conquista de América en la literatura alemana del siglo XX". Lexis 16.1 (1992): 97-112.

Otte, Enrique. "Federmann, Nicolas". Diccionario de historia de Venezuela. Ed. Manuel Pérez Vila. Vol. 2. Caracas: Fundación Polar, 1988. 153-54.

Pérez-Salazar, Carmela. Reseña de El léxico cotidiano en América a través de las Relaciones Geográficas de Indias: Tierra Firme y América del Sur, siglo XVI, de Eva Bravo-García y María Teresa Cáceres-Lorenzo. Berna: Peter Lang, 2013. Rilce 30.2 (2014): 609-13. 
Procopio, Eliabe, Fabricio Mota y Márluce Coan. "Lusismo y Tupismo en el corpus «Documentos relativos a Brasil conservados en los archivos españoles (ss. XVI-XVII)»”. Hispanista 13.50 (julio/agosto/septiembre de 2012): 1-16.

Ramírez, Arnulfo G. El español de los Estados Unidos: el lenguaje de los hispanos. Madrid: Mapfre, 1992.

Ribas, Rosa. Testimonios de la conciencia lingüística en textos de viajeros alemanes a América en el siglo ХVI. Kassel: Reichenberger, 2005.

Rodríguez Monegal, Emir. Noticias secretas y públicas de América. Barcelona: Tusquest, 1985.

Romaine, Suzanne. Bilingualism. Oxford: Blackwell, 1995.

Sánchez Lancis, Carlos. "Corpus diacrónicos y periodización del español”. Cabiers d'études hispaniques médiévales 32 (2009): 159-80.

Sánchez Sánchez, Mercedes, y Carlos Domínguez Cintas. "El banco de datos de la RAE: CREA y CORDE". Per Abbat: boletín filológico de actualización académica y didáctica 2 (2007): 137-48.

Shukla, Shaligram, y Jeff Connor-Linton. "Language Change". An Introduction to Language and Linguistics. Eds. Ralph W. Fasold y Jeff ConnorLinton. Cambridge: Cambridge UP, 2006: 275-311.

Vaquero de Ramírez, María Tránsito. "Español de América y lenguas indígenas". Estudios de Linguiística 7 (1991): 9-26.

Wagner, Erika. The Prehistory and Ethnobistory of the Carache Area in Western Venezuela. Yale University Publications in Anthropology 71. New Haven: Yale UP, 1967.

Wis, Marjatta. "Über den ältesten Einfluss des Spanischen auf die deutsche Sprache". Neuphilologische Mitteilungen 66 (1965): 619-34. 